\title{
4. VALORIZATIONS OF THEORETICAL MODELS OF GIFTEDNESS AND TALENT IN DEFINING OF ARTISTIC TALENT
}

Ionica Ona Anghel ${ }^{293}$

\begin{abstract}
Artistic talent has been defined in various contexts and registers a variety of meanings, more or less operational. From the perspective of pedagogical intervention, it is imperative understanding artistic talent trough the theoretical models of giftedness and talent. So, the aim of the study is to realize a review of the most popular of the theoretical models of giftedness and talent, with identification of the place of artistic talent and the new meanings that artistic talent has in each one. Research methodology requires a meticulous documentation and access to primary bibliographic sources. The investigation allowed us to notice that most of the models and theories of giftedness explain the phenomenon through its multidimensionality, and in this context the concept of talent is considered or component of giftedness (Feldhusen), or the concepts of giftedness and talent are discussed as synonymous (Tanenbaum, Renzulli, Heller), or the concepts of giftedness and talent are considered as distinct (Gagne). There are authors who approach the concept of giftedness without any mentioning of talent (Gardner, Sternberg). From the contribution of theoretical models of giftedness and talent to understanding of artistic talent we mention: Feldhusen describes the creative-artistic talent in the classification of the talents by their relationship with curriculum areas; Tanenbaum also carries a classification of talent by their contribution to society and considers the artists, the musicians, the actors and the writers as talents that beautifies the world, calling them "surplus talents"; Gagne, who discuss the phenomenon from the perspective of human skills development and who places the giftedness at the potentiality pole and the talent at the performance pole, includes the artistic talent on the list of various types of talents and explain the factors involved in its development; Heller, Ziggler provides explanations of talent development in the light of a new research in the field of expertise, and we can particularly apply to the artistic talent. The results of the present research are the starting point of a personal trail of understanding of artistic talent, indispensable for theoretical and/or applicative approaches of any researcher interested in the psycho-pedagogy of excellence.
\end{abstract}

Key words: giftedness, talent, theoretical models, artistic talent

\section{Giftedness and talent concepts}

Before addressing the subject of artistic talent we want to clarify a situation encountered in psycho pedagogy of excellence literature: the relationships between concepts of giftedness and talent. Romanian authors have preferred a long period of time - at least until the 90s - the differentiated approach for "giftedness" and "talent" using the concept of "giftedness" to refer to higher general intellectual abilities (Jigău M., 1994) or related to creativity (Roca 1990), and the concept of "talent" to refer to higher manifested specific skills (Begat M., 1967 Jigău M., 1994.). In the late 90s, international trends influenced Romanian authors' works. Cretu C. 1997 adopted in Global Success Model a differential meaning of the two concepts: giftedness is considered to be a high level of innate abilities expressed in a field, and the talent is considered to be systematic developed high level of abilities in different fields. In his later works

\footnotetext{
${ }^{293}$ Lecturer PhD., “George Enescu” University of Arts from Iaşi of Romania, email: ona_anghel@yahoo.com
} 
she choose to use giftedness, talent, excellence, high skills, skills above average to "designate the phenomenon of exceptionality manifested in any field socially useful" (Cretu, 2005).

On the international literature the terms giftedness and talent are most frequently used interchangeably as synonyms, receiving the necessary nuances. This is the version that we agreed since research has shown that both concepts are multidimensional, determined by internal and external factors, innate or educated. We adhere of synonymous option also because both terms are used to describe the same reality: the presence or the potentiality of outstanding performance, and whether that behavior denotes technical performance we talk about technical talent, whether that behavior denotes performance in art we talking about artistic talent, etc. In this situation both, talented in art and talented in technologies, are gifted or gifted in technology and gifted in the art.

\section{Approaches of talent and giftedness in theoretical models}

The most contemporary models and theories on talent and giftedness give it to us by the research of psycho pedagogy of excellence explain the phenomenon by its multidimensionality. Feldhusen is an author who believes that talent is one of an important element of giftedness. These two concepts have different meanings for Gagne, the talent being the expression of becoming gifted through education. For Tanenbaum, Renzulli or Heller the concepts are synonyms. There are approaches that discus the concept of giftedness without speaking about the talent in any way. They are researchers concerned with explaining cognitive functioning of giftedness, rather than explaining how it manifests. We can enumerate Gardner or Sternberg. We will achieve a review of some of the most relevant theoretical models of talent and giftedness in defining artistic talent.

\subsection{Sea star model of giftedness (Tannenbaum, 1983)}

The model offered by Tannenbaum in 1983 stipulates the presence of five components of whose combination, in different proportions for each area of talent, provides the prerequisites for giftedness. Placing in star shape of the five factors important for defining talent and giftedness gave the name of the model. In each of the five points of the star are: general ability, special aptitude, nonintellective requisites, environmental supports and chance. In the light of these factors a gifted person is " that it denotes their potential for becoming critically acclaimed performers or exemplary producers of ideas in spheres of activity that enhance the moral, physical, emotional, social, intellectual or aesthetic life of humanity" (Tannenbaum, 1986, p33).

He proposes four types of gifted and talented persons according to their contribution to society: ,the scarcity talents" are the gifted that society needs to make our lives simple, safe, healthy (e.g. the inventor of penicillin); " the surplus talents" are the gifted who beautify the world (e.g. artists, musicians, painters, writers); ,the quota talents" are people with highly specialized skills that humanity needs in order to function as a society (e.g. politicians, teachers, engineers, legislators, etc.); ,the anomalous talents" are those gifted persons that produced entertainment (e.g. circus performers, chocolatier). One of corners of the star, special aptitude, will be that will lead to a type of talent. Aptitude such 
as the precocity in understanding of sheet music or musical composition, sensitivity to colors and shapes and joined in an original manner, empathy up to identify with a character are some of the specific skills of artistic talent.

Although Tanenbaum warns us that talent will be developed to their maximum value until adulthood he admits that only through educational intervention since early ages talented individuals will be able to contribute to society. Many artists have varied skills in childhood, poli-potentiality is often present at these. Poli-potentiality is a psychological feature that brings together a valuable addition, but also a risk, many talented children making it difficult to choose the direction of performance. Tanenbaum author's perspective of looking at giftedness and talent is quite exclusive. Few will be those who will fall into one of four categories of talent, but certainly their contribution to human development will be appreciated.

\subsection{Composite conception of giftedness (Feldhusen, 1986)}

Feldhusen generically defines the giftedness on the continuum childhoodadulthood, underlined the differences on the concept taking in consideration the age of the person. He gives us an operational definition: "giftedness in child or adolescent consists of psychological and physical predisposition for superior learning and performance in the formative years and high-level achievement or performance in adulthood" (Feldhusen, 1986, p.112). To explain giftedness the author describes its main components, and talent is one of them besides the general intellectual abilities, positive self-concept and achievement motivation. Giftedness is operational redefined as "a combination of general ability, special talents, self-concept and motivation that predispose the gifted individual to learn, to achieve, to strive for excellence" (Feldhusen, 1986, p.125).

In his theory the talents represent the set of abilities in relation with a specific area of human activity and can be evaluated based on proved performances on authentic tasks. He suggests a classification of talent in relation with curriculum areas, taking in consideration three of them: 1) academic: talent in the fields of science, math, literature, social studies, computer science; 2) artistic: creativity; 3) vocational areas: family economy, industrial art, agriculture, business. The author enhances the fact that these areas and subareas could have other talent categories. For Feldhusen, the talent is a part of the giftedness in the same way that Tanenbaum thinks about the special abilities. In Feldhusen opinion the artistic-creative talent will become giftedness to a child if he proves also general intellectual abilities of a high level, and also motivation and a positive self-concept. This theory could be on a debate, because a child without a positive self-concept or high-level intellectual abilities can still show, through his behavior, a talent in artistic areas, areas that are more on a affective level than on an intellectual one.

\subsection{The three-ring conception of giftedness (Renzulli, 1977, 2005)}

For Joseph Ranzulli giftedness and talent are synonyms. The author speaks about gifted behavior or areas of talent manifestation. They are possible, but will fully appear after they evolve, in the same time with the person's evolution. In Renzulli's opinion there are two categories for giftedness: schoolhouse 
giftedness and creative-productive giftedness. Schoolhouse giftedness is found on those persons that have high scholar results and that are in most cases identified through standard tests. Creative-productive giftedness "describes those aspects of human activity and involvement where a premium is placed on the development of original material and products that are purposefully designed to have an impact on one or more target audience" (Renzulli, 1999, p. 9).

Because it wishes to include both types of giftedness, the original model of Renzulli, published in 1977, explains the phenomenon of creative-productive giftedness as being at the intersection of three categories of human characteristics: general aptitudes or more specific ones, high levels of involvement into tasks and high levels of creativity, and the schoolhouse giftedness as being at the intersection between superior abilities and involvement into tasks. The human personality and the influences from the environment will contribute to manifestation of the three categories of the human characteristics in different areas of performance, both general and specific.

In one of his following papers the author expresses the regret that "more time wasn't spent examining the research underlying these personality and environmental influences" on the three-ring components because it would be a great opportunity to add a third set of influence elements that are related to "affective traits". (Renzulli, 1999, p. 15). In 2005 he publishes an article in which the model is revised in the way that the fond for placing the three rings is completed, and to the environment and personality influences on giftedness he adds the influences of the "co-cognitive" factors. There are identified six factors: "optimism, courage, romance with a discipline, sensitivity to human concerns, physical/mental energy and vision/sense of destiny" (Renzulli, 2005, apud Davidson, 2009, p. 89).

Based on pragmatic reasons the author chooses to define not the giftedness, but the gifted behavior. This serves to teachers involved in educational programs to recognize a gifted behavior in order to be transformed into visible and measurable behaviors. Therefore, "gifted behavior consists of behaviors that reflect an interaction among three basic clusters of human traits - these clusters being above average general and/or specific abilities, high levels of task commitment, and high levels of creativity. Gifted and talented children are those possessing or capable of developing this composite set of traits and applying them to any potentially valuable area of human performance." (Renzulli, 1986, p. 73).

Literature in this field that is dedicated to understanding giftedness and talent is enriched more and more and it takes a significant step forward once it includes the affective factors. In music, plastic arts or visual arts is impossible to form outstanding behaviors without according special attention to emotional education, because there will be lot of risks, mentioning here: scholar underachievement, low self-concept, stage fright, failure in stress situations, etc. 


\subsection{The differentiated model of giftedness (Gagne, 1985)}

On Francois Gangne's approach giftedness can be understood simply as possession of outstanding innate aptitudes. Discussed in light of human competence development giftedness is the pole of potentiality on the continuum potential-achievement and talent is the pole of achievement on the same continuum (Gagne, 2009). This evolutionary process from the potential to the systematically developed aptitudes it occurs in all professional fields and outstanding innate gifts (innate aptitudes), accompanied by other factors, could predict the high level of professional achievements and the areas of talent development. This is a first idea explaining the Differentiated Model of Giftedness, an anchor idea, the concepts of giftedness and talent being clearly distinct. "Giftedness designate the possession and use of outstanding natural abilities (called aptitudes or gifts) in at least one ability domain, to a degree that places an individual at least among the top 10 percent of age peers. Talent designate the outstanding mastery of systematically developed abilities (or skills) and knowledge in at least one field of human activity to a degree that places an individual at least among top 10 percent of age peers who are ore have been active in the field "(Gagne, 2005, p.99). The model brings together six components that can be grouped in two trios (Gagne, 2004): the first trio expresses the talent development and consists in gifts, talents and talent development processes; the second trio expresses the supportive trio and describes interpersonal catalysts, environmental catalysts and chance.

The gifts include four types of innate aptitude: intellectual, creative, socioaffective, sensorimotor, aptitude who can be easily observed in childhood when environmental factors and systematic learning have not put its mark yet. They are visible on the other ages because easiness and speed of learning on new information. The talent, the second element in trio, comes from the transformation of innate aptitudes in well trained aptitudes. The diversity of talents is very large, correlated to human activity domains. Gagne named talents: academic, arts, business, leisure, social actions, sports, technology. The third element, the development process is conducted gradually when practicing and learning are systematic and can occur in four forms: maturation, spontaneous learning, deliberated practice, systematic learning. The first is determined to the biological development of each, the second is the result of daily learning and the next two are aware and involved learning resultants.

The catalysts serve to facilitate or complicate the development process, thus responsible for the transformation of superior innate aptitude in talent. First described in Gagne's model are intrapersonal catalysts which were divided into five sub-categories: physical, motivation, volition, self-management, awareness of self. Environmental catalysts include milieu (cultural, family, social, etc.), important people for the subject (parents, friends, teachers, etc.), provision or activities involving the subject (curriculum and extra-curricular clubs, etc.), major events (awards accidents, friendships, etc.). The role of chance in developing talent was first recognized by Tanenbaum, 1983 and adopted by Gagne as the third element supportive of the model. Gagne is an author who is 
very careful in using terms, in many of his articles arguing his scientific position. In an article explain for example the choice of the adjective "outstanding" to indicate the diversity of giftedness and talent and also behaviors that differentiate the gifted and talented people by the ordinary ones. He chooses not to use the terms "exceptional" or "extraordinary" that would be too restrictive. (Gagne, 2004)

\subsection{The Munich models of giftedness (Heller, 1992, 2001; Ziegler, Perleth, 1997; Perleth, 2001)}

The studies on giftedness and talent realized by the researchers from Munich have generated models to understand the phenomenon from a multidimensional perspective. The initial Munich model reinforces the reality in which for an authentic education of highly gifted persons we have to take into consideration both the personal factors (for development, also cognitive and noncognitive characteristics used into the learning process) and the environmental factors (family influences, educational style, the company of others, etc.). According to this model "giftedness is conceptualized as multifactorized ability construct within a network of noncognitive and social moderator, as well as performancerelated variables." (Heller and all, 2005, p. 148) The model consist in: seven factors who predict talent (intelligence, creativity, social competence, musicality, artistic abilities, psycho-motor skills, practical intelligence), six moderators who depend on personality characteristics (achievement motivation, hope for success, control expectations, thirst of knowledge, coping with stress, positive self-concept), moderators who depend on environment (educational style, home environmental stimulation, parental education level, family climate, school climate, etc.) and performance area of manifestations (mathematic, technology, musical-artistic area, etc.) Later the model is expanded by Ziegler and Perleth in 1997, taking into account new research on expertise and how it develops in gifted people, resulting The Munich Process Model of Giftedness. In this new model individual/ability factors (perceptual, cognitive and motor dispositions, domain specific knowledge) have the same role as predictors from initial model. According to the Process Model, a process of active learning accompanied by a facilitator fund consisting of individual, personality and environment factors, raising the level of expertise by outstanding achievement in various fields of human activity (Heller, 2005)

In the third variant of the model -The Munich Dynamic Ability-Achievement Model- developed by Perleth in 2001 are distinguished three stage of expertise development: on preschool age, on school age, on university or profession. The model indicated the presence of an individual characteristics factors who are predisposing for learning and then competence needed for crossing all expertise stages. During the first level, general skills, such as creativity or intellectual or social are targeted. Then, throughout the period of schooling, acquisitions of knowledge in different academic areas are predominating. In the third stage, the focus is on specialization and the development of expertise in a particular field. Depending on the area, specialization can begin earlier. (Heller, 2005)

2.6. Sternberg's Triarchic Model of giftedness (Sternberg, 1985) 
Sternberg's theory start from the fact that pupils and students often fail to reach their full potential of performance because of the way in which the teaching or assessment are made, most often rigid and too rarely personalized. Sternberg is a follower of multidimensionality of giftedness and therefore develops a multidimensional model which permits identification of gifted and talented people, considering the diversity of ways in which the phenomenon can be expressed to teachers or other stakeholders. The basis of the model is the concept of "successful intelligence" and the term ,triarchic derives from how the theory of successful intelligence comprises three sub-theories: a componential sub-theory, dealing with the components of intelligence; an experiential sub-theory, dealing with the importance of coping with relative novelty and of automatization of information processing; and a contextual subtheory, dealing with the processes of adaptation, shaping and selection (Taber, H., 2010, p.6). Successful intelligence is "(1) the ability to achieve one's goals in life, given one's sociocultural context, (2) by capitalizing on strengths and correcting or compensating for weaknesses (3)in order to shape and select environments (4) through a combination of analytical, creative and practical abilities" (Sternberg, 2005, p.328).

Sternberg numbered each important sequence in his model because of the efficiency of the discourse. Thus, by (1) he wishes to clarify that for every person the success can mean something else, depending on the own purposes, depending of relevant value for himself, etc. The (2)nd point states that achieving the desired goal will come to the one with successful intelligence by knowing and accepting himself and then by maximizing those traits that give strength to behaviors conducting to success and by correcting and compensating those traits which can obstruct success. The (3)rd point sustains the understanding of intelligence beyond the environmental adaptation, in the way it is usually defined. Sometimes it is useful to adapt the environment to the yourself (by modifying it), and other times, when personal principles (or other factors) prevent you to adapt to the environment or the environment to be adapted to yourself, then the old environment must be left behind in favor to a new one. For taking the correct choice between these three variants, for achieving personal goals, Sternberg gives the solution through (4)th point. "We need creative abilities to generate new ideas, analytic abilities to determine if those are good ideas, and practical abilities to implement the ideas or to convince the others of their value." (Sternberg, 2003, p. 210)

\section{Conclusions}

The theoretical models are valid in their usefulness for the society and science (Davidson, 2009), and in this case their relevance is related to the study of the artistic talent. In his list of talents Feldhusen artistic-creative talent occupies a distinct place. In this model, the concept of talent is simplistically addressed as a component of giftedness. Even the author reviewing his theoretical option for the meaning of talent and giftedness, he will adopt for talent the meaning inspired by Gagne, which is positive transformation of the remarkable aptitudes' endowment through educational intervention. (Feldhusen, 
2005). Artistic talent comes after Tanenbaum's appreciation in the "surplus talents" and will be found in the outstanding results of the musicians, painters; actors serve to beautify the world. Tanenbaum puts the portrait of giftedness in the middle of a five-pointed star and claims that each of the five elements (high general intelligence, exceptional specific abilities, non-intellectual traits, environmental support, and chance) will be present in different proportions in different areas of talent. Which should be the perfect combination in order to portray the artistic talent? It will remain as an open question for further investigations, especially since to these on may add the importance of social responsibility. Tanenbaum stresses that "it is essential for gifted people to learn that a great character should serve as a mediator of a great accomplishment, by contrary the brilliant minds may become the most destructive forces in the world" (Tanenbaum, 2000, p.447).

In the Ranzulli model of giftedness the tartistic talent finds its place in the list ofgiftedness manifestation areas. Moreover, because the model is intended to be quickly one to put in practice, the author generates also a tool to identify the potential talented persons and elaborates multiple profiles in this regard, including some relevant for the artistic field. The model stops at the education of the children and youth. For Gagne the educational interventions - regardless of their nature, formal or informal - applied to the innate skills and especially to the one specific for the arts could lead to performances that may demonstrate the presence of the artistic talent. We consider the Munich Models of Giftedness (Heller, 1992, 2001 Ziegler, Perleth, 1997 Perleth, 2001) as being very generous in that they can be consider as starting points in the study of the giftedness and talent, regardless of its manifestation's area and of the age of the persons included in the study. Extracting this from the dynamic model of abilityachievement, we can follow the evolution of the artistic talent from childhood to the youth age and even further up to its transformation into expertise, in adulthood.

Sternberg, as Renzulli and Tanenbaum, address the giftedness in terms of social contribution (Sternberg, 2005). The role of artists is special, they should promote beauty in a manner in which the value gained in a millennia of existence of humanity to transcend the present, in condition in hwo the present is so corrupted by false values easiest for in hurry public. If applied in the educational environment, Sternberg's theory could help in the professional fulfillment of many people possessing performance potential in the areas of this field. The literature reviews of the psycho-pedagogy of excellence focused on understanding the phenomenon of giftedness and talent have allowed us to synthesize a definition for the concept of "artistic talent". We consider it to be the expression of the superior endowment in different areas of the arts field, the demonstrated excellence through outstanding performances in this area, or the potential for excellence, proved by the results in various forms of evaluation. 


\section{References}

1. Davidson, J. (2009). Contemporary Models of Giftedness. In Shavinina, L., V. (Eds.) International Handbook on Giftedness, 81 - 97 , Springer Science + Business Media B.V

2. Feldhusen., J. (1986). A Conception of Giftedness, Sternberg, R., Davidson J. (Eds.), Conceptions of Giftedness, pp. 112 - 127, Cambridge University Press.

3. Gagne, F. (2004). Transforming Gifts into Talents: the DMGT as a Developmental Theory, High Ability Studies, 15(2), 119 - 145

4. Gagne, F. (2009). Debating Giftedness: Pronat vs. Antinat, LV. Shavinina (Ed.), International Handbook on Giftedness, 115 - 198, Springer Science + Business Media B.V.

5. Heller K., Perleth, C. (2005). The Munich Model of Giftedness Designed to Identify and Promote Gifted Students, Sternberg, R., S., Davidson, J., E. (Eds.) Conception of Giftedness, Second Edition, 146- 186, Cambridge

6. Renzulli, J., S. (1986). The Three-Ring Conception of Giftedness: a Developmental Model for Creative Productivity, Sternberg, R., Davidson J. (Eds.) Conceptions of Giftedness, 53 - 91, Cambridge University Press

7. Renzulli, J., S. (1999). What is This Thing Called Giftedness and How Do We Develop It? A Twenty - Five Year Perspective, Journal for the Education of the Gifted, 23(1), 3-54

8. Sternberg, R., J., Grigorenco, E. (2003). Teaching for Succesful Intelligence: Principles, Procedures, and Practices, Journal for the Education of the Gifted, 27(2/3), $207-228$

9. Taber, K., S. (2010). Celebrating a Successful and Practical Contribution to the Theory of Intelligence: an Essay Review, Education Review, 13(3), $1-40$.

10. Tannenbaum, A., J. (1986). Giftedness: a Psychosocial Approach, în Sternberg, R., Davidson J. (Eds.). Conceptions of Giftedness, 21 - 52, Cambridge University Press 